Article

\title{
Flexural Behavior of RC Members Using Externally Bonded Aluminum-Glass Fiber Composite Beams
}

Ki-Nam Hong ${ }^{1}$, Chang-Geun Cho ${ }^{2, *}$, Swoo-Heon Lee ${ }^{3}$ and Yeonho Park ${ }^{3}$

1 School of Civil Engineering, Chungbuk National University, Chungbuk 361-763, Korea; E-Mail: hong@chungbuk.ac.kr

2 School of Architecture, Chosun University, Philmundaero, Dong-Gu, Gwangju 501-759, Korea

3 Department of Civil Engineering, University of Texas at Arlington, Arlington, TX 76019, USA; E-Mails: swooheon@uta.edu (S.-H.L.); yeonho.park@mavs.uta.edu (Y.P.)

* Author to whom correspondence should be addressed; E-Mail: chocg@chosun.ac.kr; Tel.: +82-62-230-7023; Fax: +82-62-230-7155.

Received: 25 December 2013; in revised form: 26 February 2014 / Accepted: 3 March 2014 / Published: 10 March 2014

Abstract: This study concerns improvement of flexural stiffness/strength of concrete members reinforced with externally bonded, aluminum-glass fiber composite (AGC) beams. An experimental program, consisting of seven reinforced concrete slabs and seven reinforced concrete beams strengthened in flexure with AGC beams, was initiated under four-point bending in order to evaluate three parameters: the cross-sectional shape of the AGC beam, the glass fiber fabric array, and the installation of fasteners. The load-deflection response, strain distribution along the longitudinal axis of the beam, and associated failure modes of the tested specimens were recorded. It was observed that the AGC beam led to an increase of the initial cracking load, yielding load of the tension steels and peak load. On the other hand, the ductility of some specimens strengthened was reduced by more than $50 \%$. The A-type AGC beam was more efficient in slab specimens than in beam specimens and the B-type was more suitable for beam specimens than for slabs.

Keywords: aluminum-glass fiber composite (AGC) beam; flexural stiffness; flexural strength; failure mode; ductility 


\section{Introduction}

Much research has been performed to develop techniques that improve the structural performance of aging or damaged reinforced concrete members in flexure and shear. Of the strengthening methods, the externally bonded reinforcement system is the most popular and has a long history. In this external strengthening technique, steel plate, carbon fiber reinforced polymer (CFRP), glass fiber reinforced polymer (GFRP), and aramid fiber reinforced polymer (AFRP) are attached to reinforced concrete (RC) members to carry the tensile stresses.

Strengthening a RC member by employing steel plates is the most conventional technique and has been used for decades. This technique very successfully improves flexural performance [1] and shear resistance [2-5]. In particular, fasteners have been proven to be useful for enhancing the ductility of the structures [6,7]. However, a steel plate is heavy, needs many anchor bolts for attachment, and requires steady maintenance to prevent corrosion. This has led to a reduction in the use of steel plates in recent years.

Since the 1990s, FRPs, including CFRP, GFRP, and AFRP, have replaced steel plates as the preferred method of external bonded reinforcement for several reasons: (i) they are easy to handle because of light weight; (ii) they have a high strength-to-weight ratio; and (iii) they are resistant to corrosion. To date, many experimental and analytical research projects [8-10] have examined FRP sheets or rods for externally strengthening or internally reinforcing materials. The externally [11-14] or internally bonded method [15], the unbonded mechanically anchored method [16,17], the prestressing method [18-20], and the near surface mounted method [21-23] have been commonly used to apply FRP to concrete beams. Attari et al. [11] reported that the number of layers didn't have significant influence on the flexural stiffness (or strength), but the U-anchorage made the strengthening material and concrete well confined. Externally bonded (EB) CFRP laminates and steel fabrics showed good performance in increase of flexural strength, but CFRP, with higher axial stiffness compared to steel fabric, propagated the detachment of the concrete cover in the test program by Balsamo et al. [12]. In order to prevent a premature failure of a strengthened member by strip detachment in the EB system, Maaddawy and Soudki [16] showed that the end-anchorage could prevent a brittle failure by delamination of strip, in comparison with the mechanically-anchored unbonded FRP (MA-UFRP) method and the externally-bonded FRP (EB-FRP) method. Bank [17] also used the mechanically-fastened FRP (MF-FRP) method for strengthening concrete members because of the inherent speedy and immediate installation. Concrete members with mounted FRP strips showed a significant flexural performance, but several specimens had a problem of debonding [22,23]. Concrete structures strengthened with FRP showed improved flexural stiffness and strength, but brittle fracture behavior due to the material property of FRP.

Recently, several studies have been conducted to improve the flexural stiffness and strength of RC members by using high-performance fiber concrete and FRP-mixed strengthening materials [24-28]. However, these two materials each have their own problem. In the case of FRP, the strengthening system is not sufficient to ensure satisfactory strengthening of structures exposed to excessive deflection due to a sustained load or when required to improve flexural strength (or stiffness) because the FRP material has a lower modulus of elasticity than steel. The steel plate, as mentioned above, is an effective method, but its heavy weight and corrosion make it impractical for field work. 
The research discussed in this paper makes an attempt to develop a method for reducing the weight of the strengthening material and preventing corrosion. An experimental program was performed to evaluate the strengthening effect of an aluminum-glass fiber composite (AGC) beam, which consists of hollow aluminum and bonded glass-fiber fabrics.

\section{Experimental Program}

\subsection{Aluminum-Glass Fiber Composite (AGC) Beam for Strengthening}

Two AGC beams of different shapes and dimensions are shown in Figure 1. The A-type beam, with a Warren truss section, had a height of $40 \mathrm{~mm}$ and a width of $265 \mathrm{~mm}$, and the B-type beam, with a Pratt truss section, excluding diagonal members, had a height of $12 \mathrm{~mm}$ and a width of $260 \mathrm{~mm}$. The weights of the A-type and B-type beams were 3.44 and $2.89 \mathrm{kgf} / \mathrm{m}$, respectively. Both beams could be easily handled and installed due to their light weight. The AGC beam consisted of a hollow aluminum beam and laminated fiber-glass fabric.

Figure 1. Aluminum-glass fiber composite beams of (a) A-type of Warren truss section and (b) B-type of Pratt truss section.
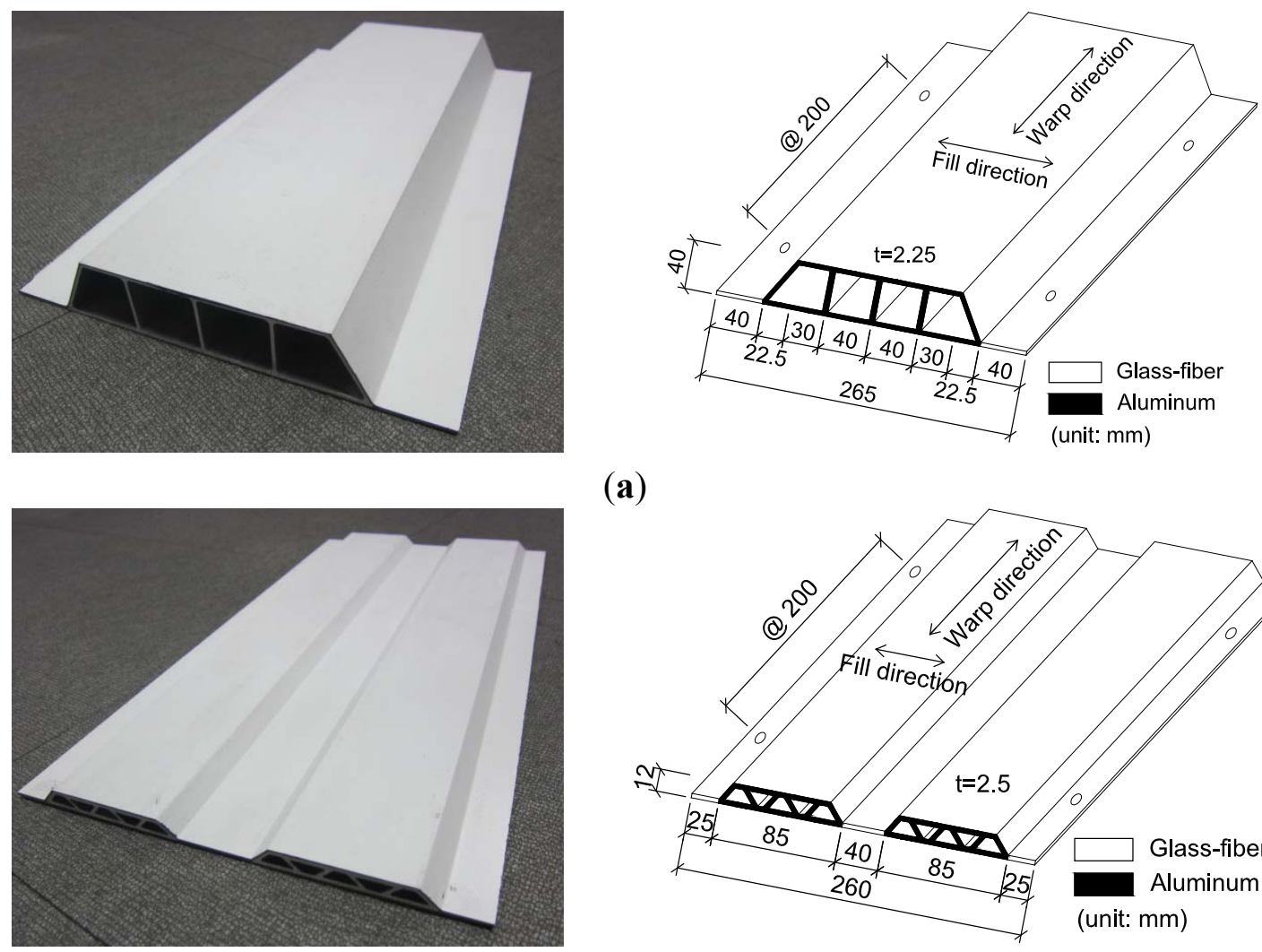

(a)

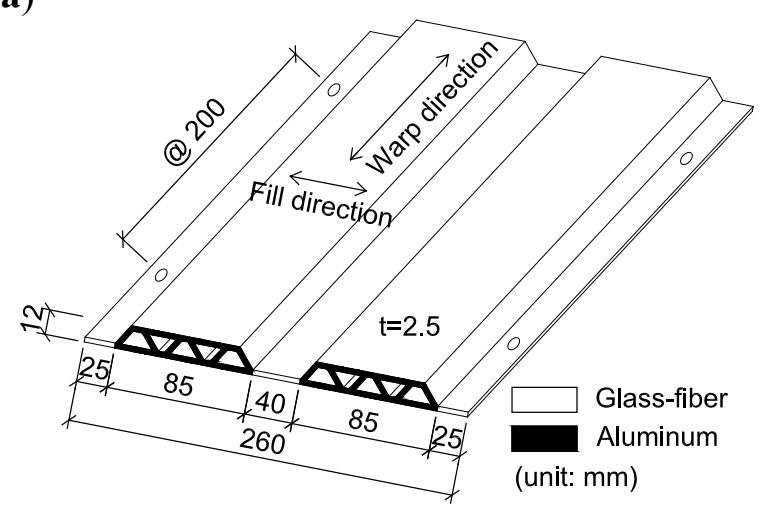

(b)

The AGC beam was manufactured at a temperature of $140{ }^{\circ} \mathrm{C}$ and pressure of $0.7 \mathrm{~N} / \mathrm{mm}^{2}$. A number of production procedures for the AGC beam were developed, as shown in Figure 2: (1) several lower fiber-glass fabric layers were laminated; (2) the aluminum beam was bonded to the lower fiber-glass; (3) several upper fiber-glass fabric layers were laminated; (4) a protective film was attached; (5) the AGC beam was pressed at high temperature; and (6) the AGC beam was demolded 
and cut. The carbon fiber has been used as strengthening material to improve the performance in deteriorated structures. In the case of composition of carbon fiber and aluminum, this composite member would be governed by fracture of carbon fiber because it is a brittle material with high tensile strength. So, in order to induce the ductile behavior and ensure the composite behavior, the glass fiber was utilized in the AGC beam because the strength and modulus of elasticity of glass fiber is similar to that of aluminum.

Figure 2. Manufacturing process of (a) lower laminated fiber-glass and aluminum beam;

(b) upper laminated fiber-glass and protection film; (c) hot- press process; and (d) demold.

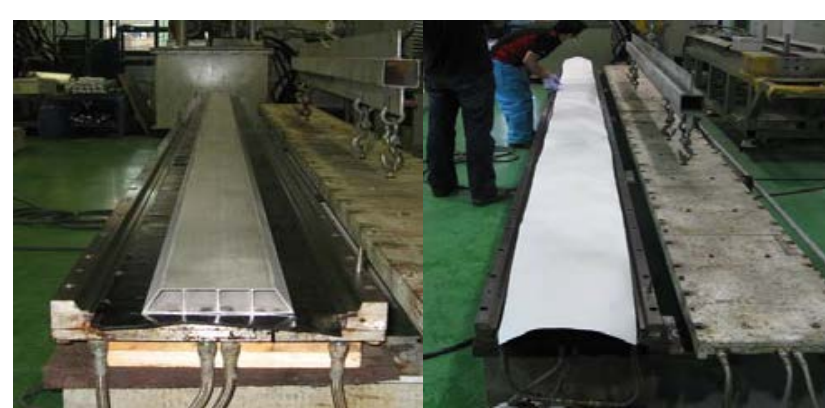

(a) (b)

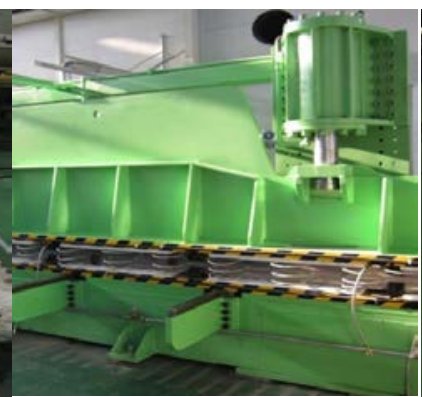

(c)

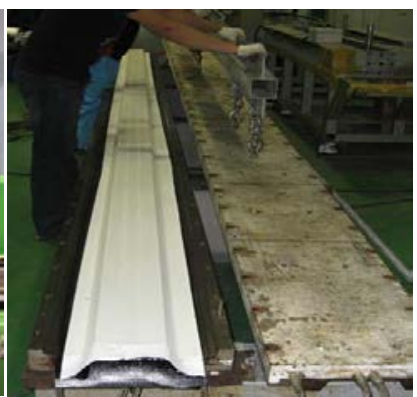

(d)

Two types of fiber-glass fabrics were used in the experimental program: (i) W40-F60 with a fiber-glass content ratio of $40 \%$ in the warp direction and $60 \%$ in the fill direction; and (ii) W80-F20 with a fiber-glass content ratio of $80 \%$ in the warp direction and $20 \%$ in the fill direction (Note that "W" and "F" represent the warp and fill, respectively). The mechanical properties (e.g., tensile strength, ultimate strain and modulus of elasticity) of the materials used in the AGC beam are given in Table 1. These average values were obtained from coupon tests of aluminum and fiber-glass cut from the manufactured AGC beam. Five coupons of the aluminum alloy $6063 \mathrm{~T} 6$ were tested according to ASTM E 8. The aluminum had an average tensile strength of $275 \mathrm{MPa}$ and an average ultimate strain of 0.053. Also, five coupons each of each W40-F60 and W80-F20 fiber glass were tested in accordance with ASTM D 3039/D 3039M. The average tensile strengths in the fiber-glass of W40-F60 and W80-F20 were 246 and $496 \mathrm{MPa}$, respectively, which were proportional to content ratio in the warp direction.

Table 1. Physical properties of materials comprising aluminum-glass fiber composite (AGC) beam.

\begin{tabular}{cccc}
\hline \multirow{2}{*}{ Materials } & Tensile strength (MPa) & Ultimate strain & Modulus of elasticity (GPa) \\
\cline { 2 - 4 } & CoV & CoV & CoV \\
\hline Aluminum alloy 6063 T6 & 275 & 0.053 & 71.5 \\
& $5.8 \%$ & $6.1 \%$ & $3.1 \%$ \\
Glass-fiber of W40-F60 & 246 & 0.017 & 14.7 \\
& $10.3 \%$ & $9.2 \%$ & $4.5 \%$ \\
Glass-fiber of W80-F20 & 496 & 0.016 & 31.0 \\
& $9.5 \%$ & $11.1 \%$ & $5.2 \%$ \\
\hline
\end{tabular}




\subsection{Description of Specimens}

A total of 14 specimens were prepared. The specimens consisted of two different sets of $3600 \mathrm{~mm}$ long slabs and beams with a cross-section of $600 \mathrm{~mm} \times 200 \mathrm{~mm}$ (Group I) and $300 \mathrm{~mm} \times 450 \mathrm{~mm}$ (Group II). In the case of slab specimens, the reinforcement consisted of five D13 bars with diameters of $12.7 \mathrm{~mm}$. In the case of beam specimens, four tension steel bars of D16 with diameters of $15.9 \mathrm{~mm}$ were used. Stirrups of D10 with diameters of $9.53 \mathrm{~mm}$ were placed at $100 \mathrm{~mm}$, center-to-center to avoid shear failure in all specimens (see Figure 3). In each group, one specimen was a control specimen, and six specimens were strengthened with two different AGC beams. The strengthening (or bonding) length of the AGC beam was about $90 \%$ of the span length. The variables in the two tested groups included: (i) fiber-glass of W80-F20 and W40-F60; (ii) AGC beam of A-type and B-type; and (iii) an additional fastener for the combination of the RC beam and the AGC beam (see Table 2). Because the AGC beam should be attached at the bottom of the existing beam, the fastener needs to be fixed at the beam in order to support the self-weight of the AGC beam until the epoxy adhesive has been hardened. It was installed for improvement in construction. Fasteners were also studded at $200 \mathrm{~mm}$ spacing to fix the AGC beam strengthening system with the chemical bonding of the epoxy adhesive. The nomenclature of test specimens is as follows: the first character, "I" or "II", represents the series of specimens ("I" is for slab specimens and "II" is for beam specimens); the second character, "G8" or "G4", indicates W80-F20 and W40-F60 according to the content ratio of fiber-glass in warp direction, respectively; the third term, "A" or "B", represents two different cross-sections of the AGC beam; "NF" means no installation of fastener; and "I-Ref" and "II-Ref" are the references for slab and beam specimens, respectively.

Figure 3. Details of test specimens of (a) slab specimen and (b) beam specimen.
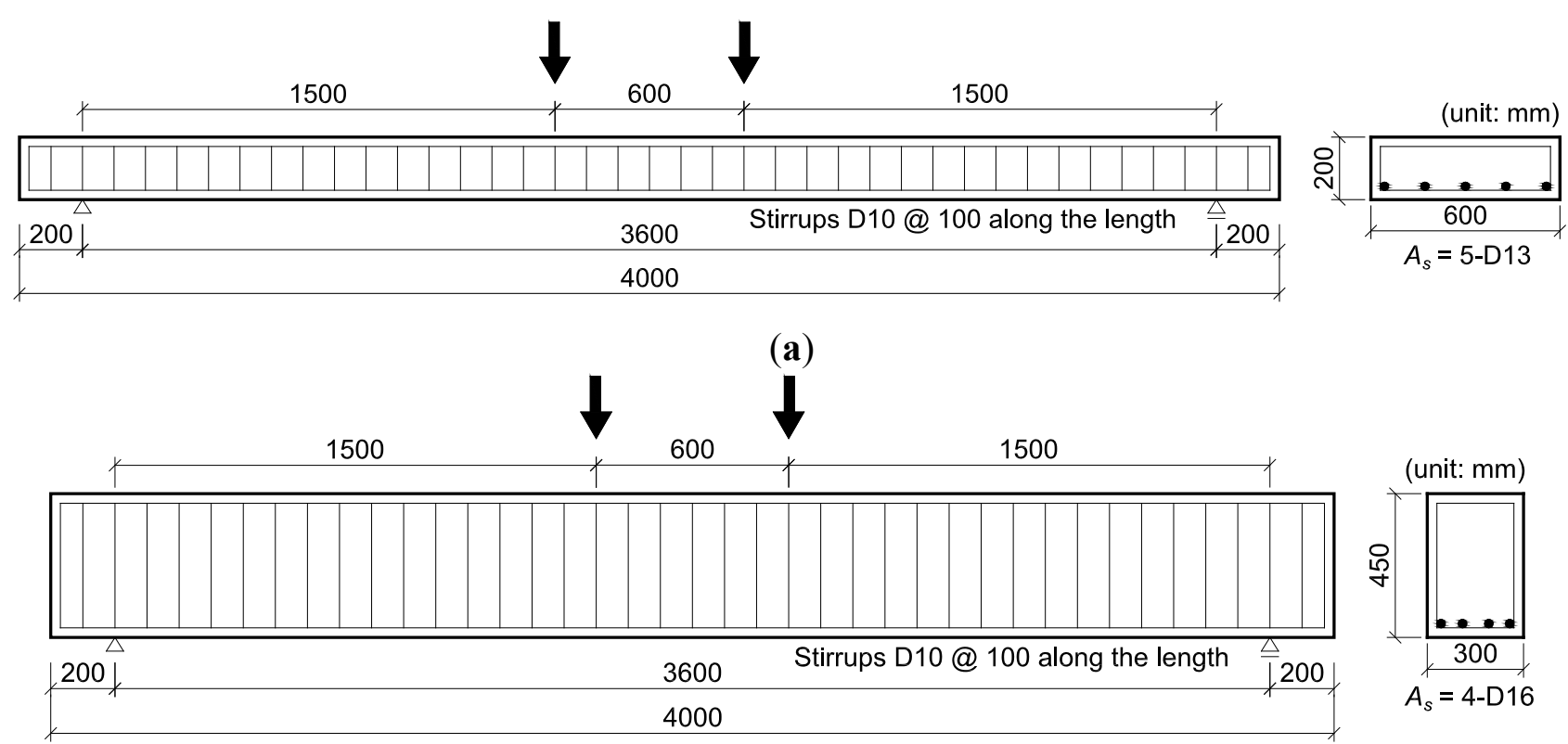

(b) 
Table 2. Matrix of specimens.

\begin{tabular}{ccccc}
\hline Group & Specimen & Glass fiber type & AGC beam type & Fastener \\
\hline & I-Ref & - & - & - \\
& I-G8-A & W80-F20 & A & Installation \\
Slab group & I-G8-B & W80-F20 & B & Installation \\
(Group I) & I-G4-A & W40-F60 & A & Installation \\
& I-G4-B & W40-F60 & B & Installation \\
& I-G4-A-NF & W40-F60 & A & No installation \\
& I-G4-B-NF & W40-F60 & B & No installation \\
\hline & II-Ref & - & - & - \\
Beam group & II-G8-A & W80-F20 & A & Installation \\
(Group II) & II-G8-B & W80-F20 & B & Installation \\
& II-G4-A & W40-F60 & A & Installation \\
& II-G4-B & W40-F60 & B & Installation \\
& II-G4-A-NF & W40-F60 & A & No installation \\
& II-G4-B-NF & W40-F60 & B & No installation \\
\hline
\end{tabular}

\subsection{Material Properties}

The concrete mixtures were made of ordinary Type I Portland Cement and crushed aggregates with a maximum size of $25 \mathrm{~mm}$. The compression tests of three cylinders with $\phi 100 \mathrm{~mm} \times 200 \mathrm{~mm}$ were carried out according to ASTM C 39/C 39M. The average compressive strength of concrete cylinders was $22.2 \mathrm{MPa}$ at 28 days and it was $22.6 \mathrm{MPa}$ at the age of the tests of the beams and slabs. The coefficients of variation $(\mathrm{CoV})$ for compressive strength of concrete were $2.1 \%$ and $1.9 \%$ at 28 days and main loading tests, respectively. The mixing design per $\mathrm{m}^{3}$ of concrete was: $306 \mathrm{~kg}$ cement, $913 \mathrm{~kg}$ sand, $901 \mathrm{~kg}$ crushed aggregate, $1.53 \mathrm{~kg}$ superplasticizer, and $163 \mathrm{~L}$ water. The water-cement ratio (W/C) and sand-aggregate ratio (S/a) were 53.2\% and 50.3\%, respectively. The tensile test results of three deformed steel bars used in the specimens are shown in Table 3, respectively. Three coupons of each bar were tested to confirm the mechanical properties in accordance with ASTM A 370. The average yield strengths were $518 \mathrm{MPa}$ for D10 bars with diameter of $9.53 \mathrm{~mm}, 494 \mathrm{MPa}$ for D13 bars with diameter of $12.7 \mathrm{~mm}$, and $506 \mathrm{MPa}$ for D16 bars with diameter of $15.9 \mathrm{~mm}$, respectively. The average ultimate strengths were $616 \mathrm{MPa}$ for D10 bars, $610 \mathrm{MPa}$ for D13 bars, and $608 \mathrm{MPa}$ for D16 bars, respectively. The properties of the epoxy adhesive used to attach the AGC beam to the bottom of the RC beam are: $97 \mathrm{MPa}$ compressive strength, $45 \mathrm{MPa}$ tensile strength, and 6.1 $\mathrm{MPa}$ bonding strength, as offered from the epoxy manufacturer. The bond strength of the epoxy was much smaller than the compressive and tensile strengths of the other materials, including epoxy itself. The fastener, added in combination with the RC beam and AGC beam, was $29.3 \mathrm{~mm}$ in length and $3.7 \mathrm{~mm}$ in diameter, as shown in Figure 4. 
Table 3. Mechanical properties of deformed steel bars.

\begin{tabular}{ccc}
\hline \multirow{2}{*}{ Reinforcements } & Yield strength (MPa) & Tensile strength (MPa) \\
\cline { 2 - 3 } & CoV & CoV \\
\hline D10 (diameter of 9.53 mm) & 518 & 616 \\
& $2.4 \%$ & $3.5 \%$ \\
D13 (diameter of 12.7 mm) & 494 & 610 \\
& $1.2 \%$ & $2.1 \%$ \\
D16 (diameter of 15.9 mm) & 506 & 608 \\
& $1.8 \%$ & $1.7 \%$ \\
\hline
\end{tabular}

Figure 4. Fastener for added combination of reinforced concrete (RC) beam and AGC beam.

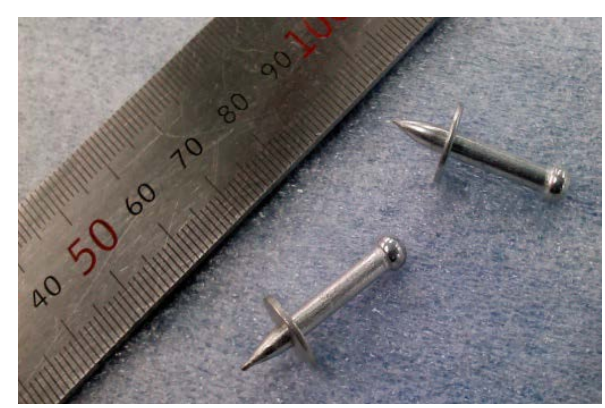

\subsection{Strengthening Technique}

The AGC beam was attached to the bottom of the RC beam after the curing period of 28 days using the chemical adhesive and mechanical fasteners. The strengthening procedure used to bond the AGC beam to the tensile surface of concrete members involved surface preparation for better attachment, application of epoxy primer, undercoating of the epoxy adhesive on the tensile surface, and application of the AGC beam. Special consideration was given to surface preparation before the application of epoxy. The concrete surface was cleaned using a uniform mechanical grinding, and the dust and grease were removed by compressed air. Primer was applied to fill any pores and level the concrete surface. After the primer was fully set, the epoxy adhesive was applied to the primer coating. Of the twelve strengthening specimens, eight specimens (four slabs and four beams) had the fasteners with $200 \mathrm{~mm}$ spacing on the AGC beam. In the remained four specimens out of twelve, the epoxy was used as the sole adhesive to compare with the effect of fasteners. All specimens were kept in a controlled environment for 7 days prior to testing to guarantee full curing of the epoxy adhesive.

\subsection{Test Setup and Instrumentation}

All specimens were simply supported and loaded in four-point bending as shown in Figure 5, and were tested until the attached AGC beam failed or was debonded. The clear span of the concrete member was $3600 \mathrm{~mm}$ and the distance between the two loading points was $600 \mathrm{~mm}$, symmetrically located from the mid-span location. Two-linear variable differential transformers (LVDTs) were placed at the mid-span to measure the deflection. Additionally, nine strain gauges (two in tension reinforcement at mid-span and seven along the longitudinal axis of the AGC beam) were employed to observe the strains of the tensile reinforcement and AGC beam during the flexural test. The specimens 
were tested under load control within the elastic range and then were loaded by displacement control until the test end. The development of concrete cracks and deformation of the AGC beam were visually observed and marked during the test.

Figure 5. Four-point bending test setup.

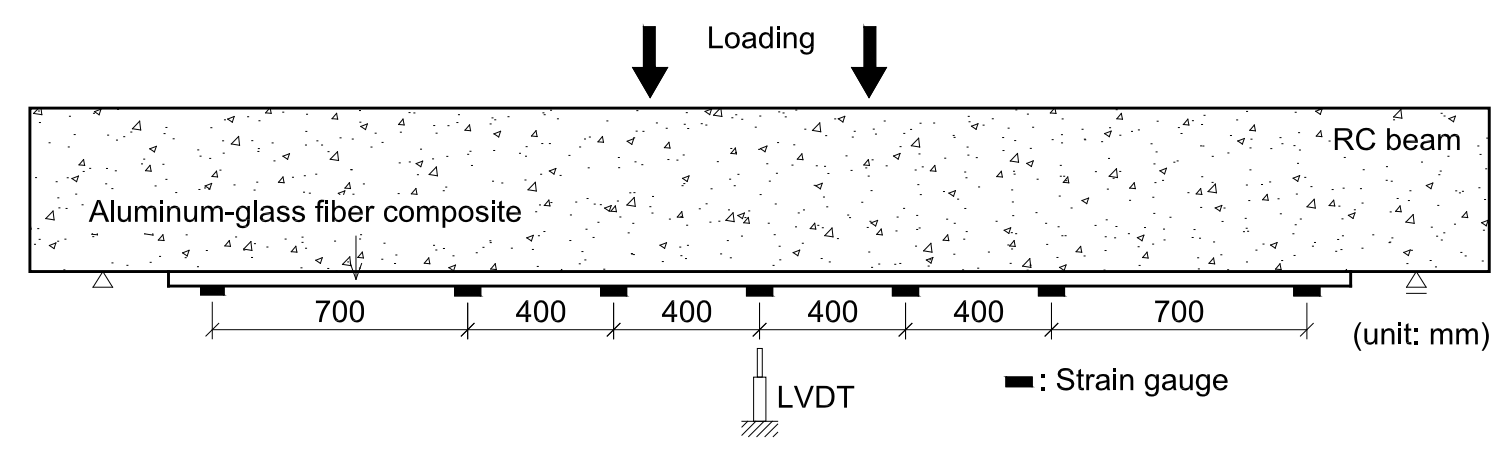

\section{Test Results}

\subsection{General Behavior and Failure Mode}

The tested RC beams presented different failure modes such as concrete crushing, and fracture and/or debonding of the attached AGC beam. The failure modes of the test specimens are shown in Figure 6 and summarized in Table 4. The process of cracking proceeded similarly in all strengthened beams.

Figure 6. Failure modes of strengthening specimens of (a) fracture of AGC beam and (b) debonding of AGC beam.

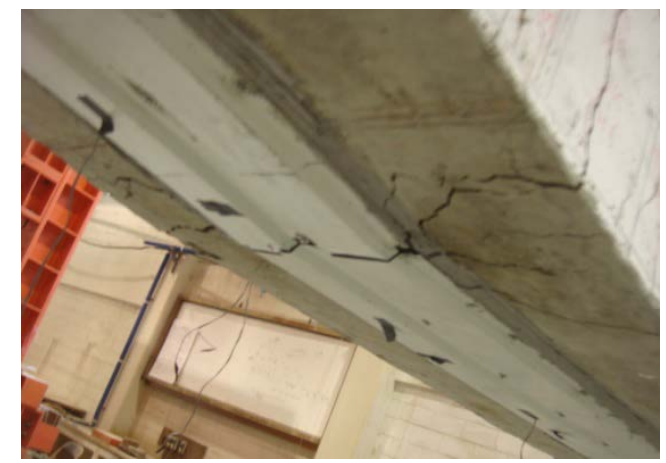

(a)

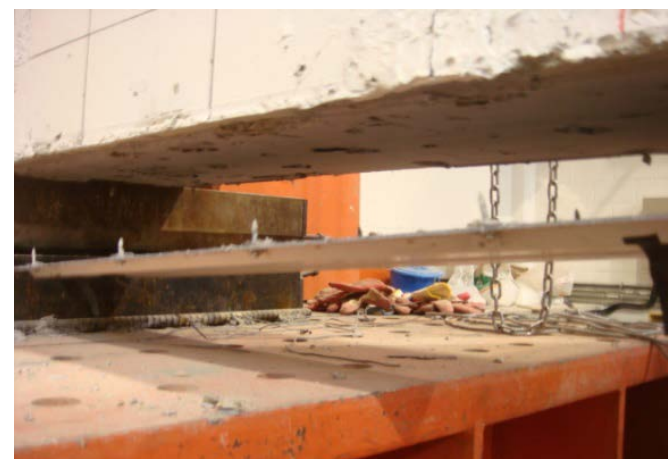

(b)

The control beams of I-Ref (of slab) and II-Ref (of beam), with no strengthening by the AGC beam, failed in flexure with concrete crushing after yielding of the tension reinforcement at mid-span. Typical flexural cracks at mid-span in I-Ref and II-Ref specimens were developed initially due to positive moment and were propagated vertically with the increased load. Subsequently, the plastic hinges were formed around two loading points, and the deflections increased steadily without a rapid load increase. 
Table 4. Summary of test results.

\begin{tabular}{ccccccccccc}
\hline Specimen & $\begin{array}{c}\boldsymbol{P}_{\mathbf{c r}} \\
(\mathbf{k N})\end{array}$ & $\begin{array}{c}\boldsymbol{P}_{\mathbf{y}} \\
\mathbf{( k N )}\end{array}$ & $\begin{array}{c}\boldsymbol{P}_{\text {peak }} \\
(\mathbf{k N})\end{array}$ & $\begin{array}{c}\text { Increase } \\
\text { for } \boldsymbol{P}_{\mathbf{c r}}\end{array}$ & $\begin{array}{c}\text { Increase } \\
\text { for } \boldsymbol{P}_{\mathbf{y}}\end{array}$ & $\begin{array}{c}\text { Increase } \\
\text { for } \boldsymbol{P}_{\text {peak }}\end{array}$ & $\begin{array}{c}\boldsymbol{\delta}_{\mathbf{y}} \\
(\mathbf{m m})\end{array}$ & $\begin{array}{c}\boldsymbol{\delta}_{\text {peak }} \\
(\mathbf{m m})\end{array}$ & $\boldsymbol{\delta}_{\text {peak }} / \boldsymbol{\delta}_{\mathbf{y}}$ & $\begin{array}{c}\text { Failure } \\
\text { Mode }\end{array}$ \\
\hline I-Ref & 7.0 & 53.9 & 72.4 & - & - & - & 26.0 & 136.0 & 5.23 & Flexure \\
I-G8-A & 18.4 & 100.6 & 137.4 & 1.63 & 0.87 & 0.90 & 24.9 & 55.5 & 2.23 & Debonding \\
I-G8-B & 13.9 & 101.2 & 113.7 & 0.99 & 0.88 & 0.57 & 34.4 & 49.2 & 1.43 & Debonding \\
I-G4-A & 13.2 & 111.4 & 117.4 & 0.89 & 1.07 & 0.62 & 33.2 & 38.6 & 1.16 & Fracture \\
I-G4-B & 13.9 & 93.5 & 97.9 & 0.99 & 0.73 & 0.35 & 31.6 & 79.3 & 2.51 & Fracture \\
I-G4-A-NF & 16.5 & 119.6 & 131.6 & 1.36 & 1.22 & 0.82 & 33.4 & 46.1 & 1.38 & Debonding \\
I-G4-B-NF & 13.8 & 82.6 & 105.5 & 0.97 & 0.53 & 0.46 & 26.3 & 54.4 & 2.07 & Debonding \\
\hline & & & & & Beam group & & & & \\
\hline II- Ref & 37.2 & 197.2 & 215.3 & - & - & - & 14.8 & 52.3 & 3.53 & Flexure \\
II-G8-A & 50.0 & 304.0 & 321.7 & 0.34 & 0.54 & 0.49 & 17.0 & 19.5 & 1.15 & Debonding \\
II-G8-B & 40.8 & 298.8 & 324.6 & 0.10 & 0.52 & 0.51 & 17.3 & 25.5 & 1.47 & Debonding \\
II-G4-A & 56.7 & - & 282.1 & 0.52 & - & 0.31 & - & 14.6 & - & Debonding \\
II-G4-B & 43.9 & 284.4 & 302.7 & 0.18 & 0.44 & 0.41 & 16.9 & 22.2 & 1.31 & Debonding \\
II-G4-A-NF & 58.5 & - & 314.0 & 0.57 & - & 0.46 & - & 15.6 & - & Debonding \\
II-G4-B-NF & 59.1 & 291.6 & 331.8 & 0.59 & 0.48 & 0.54 & 16.2 & 29.0 & 1.79 & Debonding \\
\hline
\end{tabular}

Notes: $P_{\text {cr }}$ is the cracking load; $P_{\mathrm{y}}$ is the yielding load; $P_{\text {peak }}$ is the peak load when the test was over; $\delta_{\mathrm{y}}$ is the yield deflection; and $\delta_{\text {peak }}$ is the deflection corresponding to $P_{\text {peak }}$. (1) Flexure: Concrete crushing after tension reinforcement yielding; (2) Fracture: Tensile fracture of AGC beam; (3) Debonding: Detachment of AGC beam from tension surface of RC beam.

However, there were two different primary types of failure modes in $\mathrm{RC}$ members strengthened with the AGC beam compared with control specimens as described in Table 4. The first failure mode was a fracture of the AGC beam itself. An AGC beam fracture occurred in the mid-span, as shown in Figure $6 \mathrm{a}$, after the tension reinforcement's yielding. The fracture of the AGC beam started from the extreme edge of the fiber-glass fabric, followed by the fracture of the aluminum inside the AGC beam. In specimens of I-G4-A and I-G4-B, the load was abruptly decreased with glass-fiber fracture at first peak load and then it was slightly increased until the aluminum of AGC beam failed in tensile fracture. However, the second peak load did not reach the first peak load. The second failure mode was a debonding of the AGC beam, which occurred in most of strengthening slabs (excluding I-G4-A and I-G4-B) and all strengthening beams, as shown in Figure 6b. Based on observations during the test, the progressive debonding was not observed in the early stages as the load was increased. The debonding failure of the premature failure occurred as the load was increased since the shear stress between the bonding zone of the concrete and the AGC beam exceeded the epoxy bonding strength. The debonding of the AGC beam was started from the end of the AGC beam where the shear stress was at maximum value.

Since the inclined cracking within shear span make the strengthening AGC beam debonded, an efficient anchorage at both ends of the strengthening AGC beam, such as a U-anchorage which effectively clamps the strengthening material on the tension face of the concrete beam is required. A new anchorage is needed to restrain the shear cracking and prevent the AGC beam from pre-initiating the debonding. 


\subsection{Load-Deflection Response}

Figures 7 and 8 illustrate the applied load versus mid-span deflection curves of the slabs and beams, respectively. The crack load $\left(P_{\text {cr }}\right)$, yield load $\left(P_{\mathrm{y}}\right)$, peak load $\left(P_{\text {peak }}\right)$, corresponding deflections $\left(\delta_{\mathrm{y}}\right.$ and $\left.\delta_{\text {peak }}\right)$, and ductility $\left(\delta_{\text {peak }} / \delta_{\mathrm{y}}\right)$ of each specimen are summarized in Table 4 . It was clearly observed that the strengthened specimens have larger peak load and post-cracking stiffness than those of the control specimens, however they failed at much less deflection. The increased peak load of the strengthened specimens ranged from $31 \%$ to $90 \%$ of the control specimens. Most strengthened specimens failed due to the debonding of the AGC beam. Two specimens of I-Ref and II-Ref, without the AGC beam, exhibited typical concrete structural behavior. The deflection increased linearly with increased load in the early loading stage. The stiffness was reduced on the onset of the tension crack in the concrete at about $10 \%$ and $18 \%$ of the ultimate load, respectively. After the cracks had stabilized, the load and deflection increased linearly again until the internal reinforcements reached yielding. Then, the deflection increased steadily with little increased load because the sections had been plasticized.

In the case of slab specimens, the initial crack loads in the strengthened slabs were increased by $89 \%$ to $163 \%$ compared with $7 \mathrm{kN}$ of I-Ref. The yield loads were also increased by $53 \%$ to $122 \%$ (Note that yield load is defined as when the steel starts to yield.) In specimens of I-G8-A and I-G8-B, the tests were terminated due to the debonding of the AGC beam at deflections of about $55 \mathrm{~mm}$ and $50 \mathrm{~mm}$ (corresponding to first peak loads of 137 and $114 \mathrm{kN}$ ), respectively. In contrast, I-G4-A and I-G4-B specimens failed initially in the AGC beam with fracture at deflection of about $38 \mathrm{~mm}$ (corresponding to first peak loads of 117 and $98 \mathrm{kN}$ ), respectively. Consequently, it can be seen that the content ratio of fiber-glass in the warp direction tended to govern the failure mode. Since the strength of W80-F20 in the warp direction was greater than that of W40-F60, the slab set with W80-F20 failed in debonding at larger deflections versus the failure deflections of the slab set with W40-F60. The slab specimens with W80-F20 exhibited higher strength when compared to the slab specimens with W40-F60. However, the content ratio of fiber-glass did not significantly affect the flexural stiffness which is dependent on the section shape. Additionally, the A-type AGC beam (Warren truss section) was better than the B-type (Pratt truss section) in terms of strength. However, both types need to be considered more in terms of ductility. The ductility index is defined as the ratio of failure deflection $\left(\delta_{\mathrm{u}}\right)$ and yield deflection $\left(\delta_{\mathrm{y}}\right)$. Ductility was reduced by more than half of the ductility of the I-Ref specimen due to premature failure of the strengthened AGC beam (see Table 4).

Similarly, the AGC beam had the highest increase of the load carrying capacity in flexural beam specimens of Group II. The rates of increase ranged from $10 \%$ to $59 \%$ for crack load and $44 \%$ to $54 \%$ for yield load compared with the II-Ref specimen. In specimen II-G4-A, however, the debonding of the AGC beam was observed prior to tension reinforcement yielding. The first peak load also increased by $31 \%$ to $54 \%$ in comparison to the control beam; whereas a deflection reduction of more than $45 \%$ was recorded. The strengthening effect of the AGC beam in both the beam and slab specimens was sufficient in terms of the increase of strength. However the reduction of ductility needs further consideration. 
Figure 7. Load-deflection responses of slab specimens with (a) glass-fiber of W80-F20 and (b) glass-fiber of W40-F60.

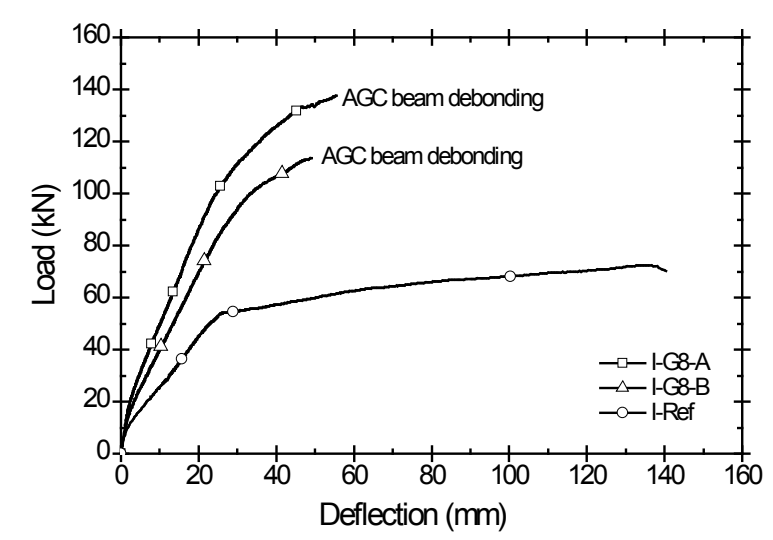

(a)

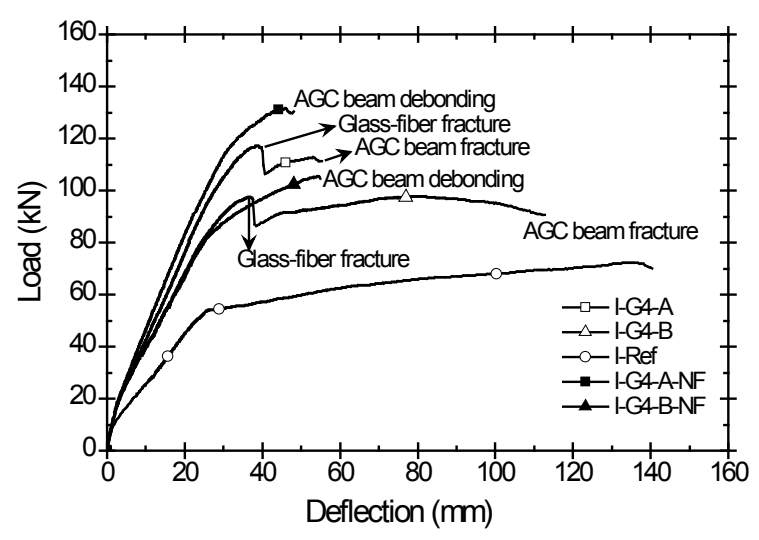

(b)

Figure 8. Load-deflection responses of beam specimens with (a) glass-fiber of W80-F20 and (b) glass-fiber of W40-F60.

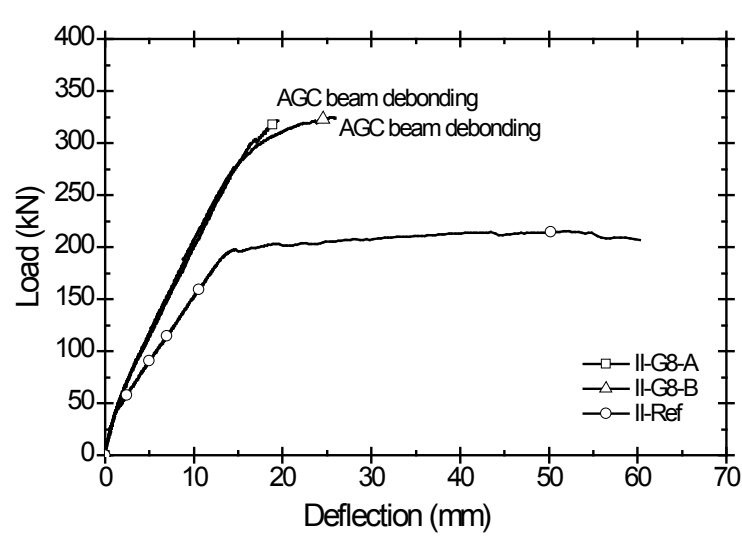

(a)

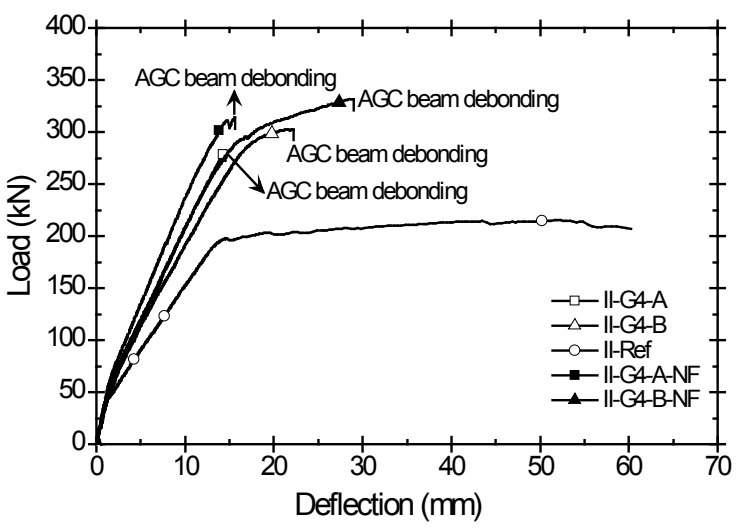

(b)

\subsection{Strain Distribution of AGC Beam}

Strains in the AGC beam at seven different locations along the beam axis were measured from the attached strain gages during the flexural testing. Figure 9 shows the strain distribution of the AGC beam along the beam axis at four load levels in specimens of I-G8-A, I-G8-B, II-G8-A, and II-G8-B. The strain distribution showed a symmetric tendency with respect to the center of the beam until the test was over. The variation of strain increased proportionally to applied load until the tension steel reached yielding. After this stage, a major change in strain profile was measured in most specimens, with the exception of the specimens that failed prematurely in fracture prior to tension steel yielding. The maximum strains were exhibited at mid-span and the measured values were 9156, 6593, 4129, and $6276 \mu \varepsilon$ in each specimen, respectively. However, the actual strain curve might be flat from -300 to $300 \mathrm{~mm}$ because this region was subjected to pure bending. It could be assumed that the strain distribution within the pure bending zone is the same as the maximum measured value at mid-span. Compared with the ultimate strain of 0.016 , based on the tensile test of W80-F20 (see Table 1), the strains were measured in $26 \%$ to $57 \%$ of ultimate strain. That means that the AGC beams in all 
specimens were fractured or debonded from the RC member, without sufficient longitudinal deformation. One strain gauge of II-G8-A in Figure 9c that was attached near the extreme end of the AGC beam (1500 mm in the left direction from beam center) was damaged just before debonding. Thus, the value from this gauge was not plotted. The strain obtained from the strain gauge (attached at $1500 \mathrm{~mm}$ in the right direction from beam center) of II-G8-B in Figure 9d increased steadily until the yield load was reached, but after that, the strain value started to decrease, showing signs of debonding.

Figure 9. Strain distribution along AGC beam axis of (a) I-G8-A; (b) I-G8-B; (c) II-G8-A; and (d) II-G8-B.

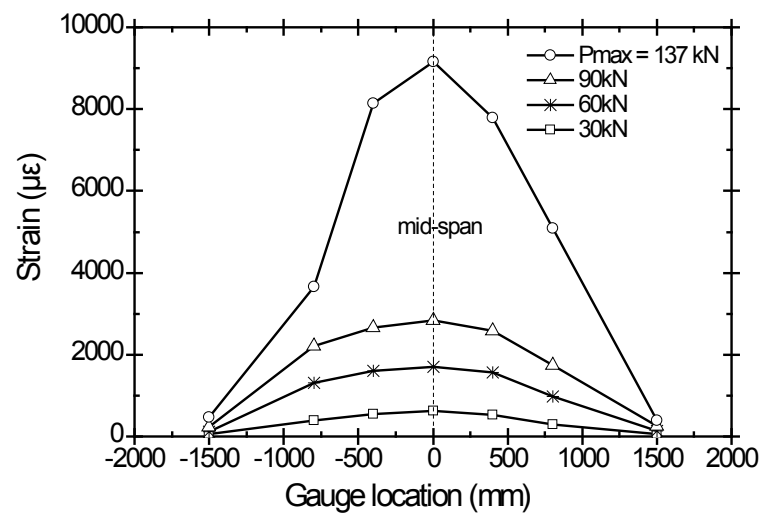

(a)

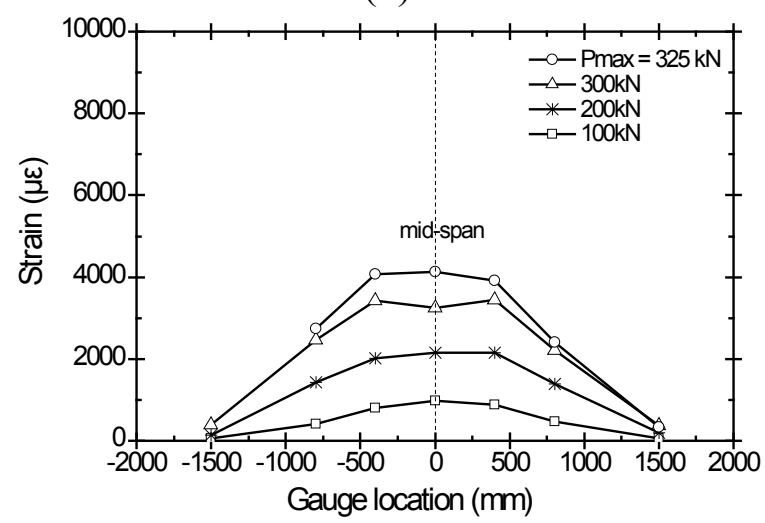

(c)

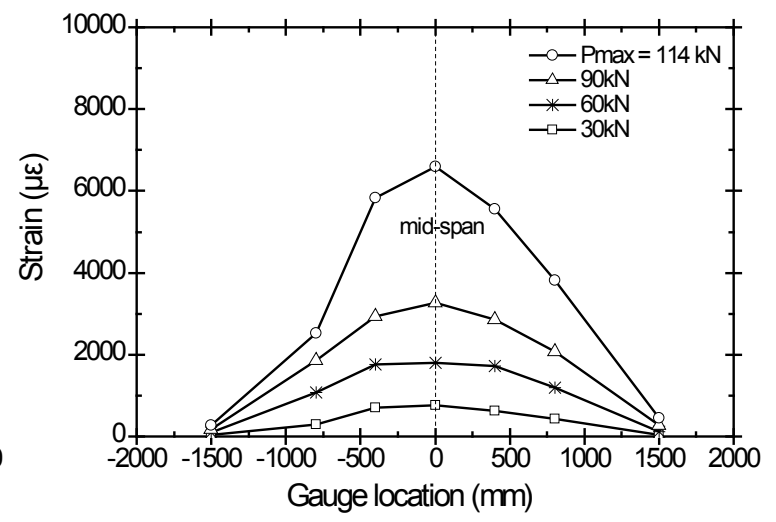

(b)

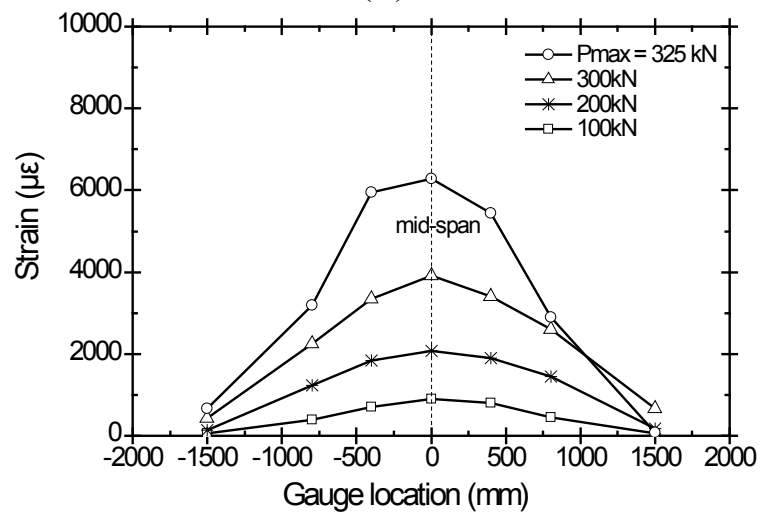

(d)

\subsection{Effect of AGC Beam Type, Glass-Fiber Array and Fastener}

The A-type and B-type AGC beams were produced to enhance the flexural stiffness (or strength) and ductility of RC members. Test results of slab specimens strengthened with A-type (I-G8-A and I-G4-A), with respect to the flexural stiffness or peak load, were higher than those of I-G8-B and I-G4-B strengthened with the B-type beam (see Figure 7). In beam specimens, however, the flexural stiffness of the specimens with A-type and B-type appeared similar (see Figure 8). The slabs with A-type obtained a strengthening effect in terms of flexural stiffness (or strength). However, in the case of beams, A-type strengthening did not impact the flexural performance, and unfortunately resulted in premature debonding failure. The content ratio of glass-fiber in the warp direction appeared to have a slight effect on the increase of flexural stiffness (or strength), as shown in Figures 7 and 8 . In the 
specimen I-G4-A, the fracture of the AGC beam might have occurred due to the small amount of fiber in the warp direction.

Fasteners also have no significant effect on the flexural stiffness or strength (see Figures $7 \mathrm{~b}$ and $8 \mathrm{~b}$ ). Unfortunately, the fastener and its corresponding hole led to fracture of the AGC beam (see Figure 10). The stress concentration in an orthogonal direction of beam axis around the hole occurred against longitudinal deformation, and the fracture started from the stress concentrated parts. The AGC beam eventually broke into two pieces around a fastener. The fasteners, used in the form of nails, do not seem to be an ideal and practical solution since fasteners (anchor of nail type) and its corresponding hole led to stress concentration around the holes and fracture of the AGC beam and it also did not control the debonding of AGC beam caused by inclined shear cracking. Based on the test results by Khalifa et al. [29], they showed that the U-anchor and U-wrap were compatible with bonded strengthening system by FRP sheet. It could be suggested that a better anchoring solution would be a U-anchorage used within the shear span so that the inclined shear cracking would not precipitate the debonding of the AGC beam, which has occurred in most of the tested specimens.

Figure 10. Fracture of AGC beam around fastener.

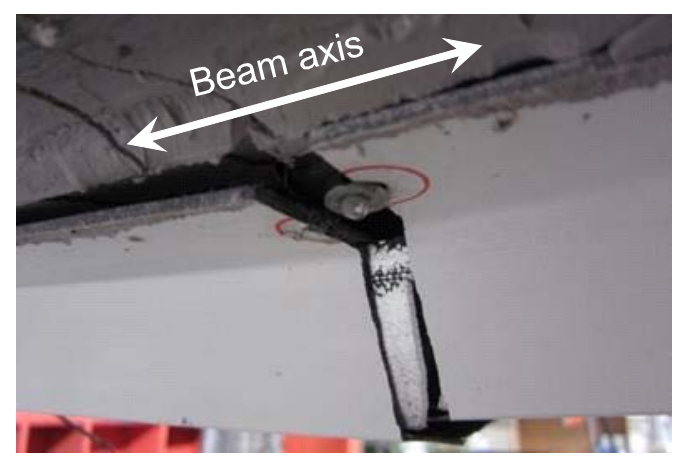

As test results reflect, the AGC strengthening system increased the flexural strength and stiffness in reinforced concrete members. However, the problems of the pre-debonding or pre-fracture of the AGC beam before it reached yielding were detected at flexural tests. To avoid the premature failure due to debonding of the AGC beam, mechanical connection between the concrete member and the AGC beam should be considered. The debonding of the AGC beam, due to the inclined cracking within the shear span, could be prevented by using a new clamp such as a U-anchorage. Also, the stress concentration was detected around holes of small fasteners installed to improve construction, and this phenomenon led to premature failure of AGC beam. Therefore, the minimum fasteners should be studded at locations where the tensile force is not large. If the two problems of debonding and stress concentration are solved, the strengthening industry can capitalize on the light weight and strengthening effect of AGC system.

\section{Analysis Model for Moment Capacity}

\subsection{Assumptions}

To predict the moment capacity of the strengthened RC beam with the AGC beam, a simple analysis was conducted in this study. The basic assumptions are as follows: 
(i) the bending section before and after bending deformation remains plane;

(ii) the strain distribution at the section is linear from the extreme compressive fiber to the AGC beam attached at the bottom (that is, the epoxy adhesive between the beam bottom and the top of the AGC beam perfectly transmits the shear stress.);

(iii) the tensile strength of concrete is neglected;

(iv) elasto-perfectly plastic behavior is applied to the internal reinforcements and the aluminum inside the AGC beam;

(v) the glass-fiber of the AGC beam has a constant modulus of elasticity until it reaches ultimate strength; and

(vi) the effective depth of the AGC beam is from the extreme surface of the concrete to the AGC beam's centroid.

\subsection{Analysis Model at Ultimate}

This section presents the prediction of the ultimate moment capacity of the strengthened RC beams based on the ultimate strength design method. Since an AGC beam consists of aluminum and glass-fiber, it was assumed, for simplicity, that the two materials deform separately, as shown in Figure 11. In addition, the aluminum was assumed to be perfectly elasto-plastic, like steel reinforcement, even though it has no discernible yield point.

Figure 11. Strain and stress distribution at critical section.
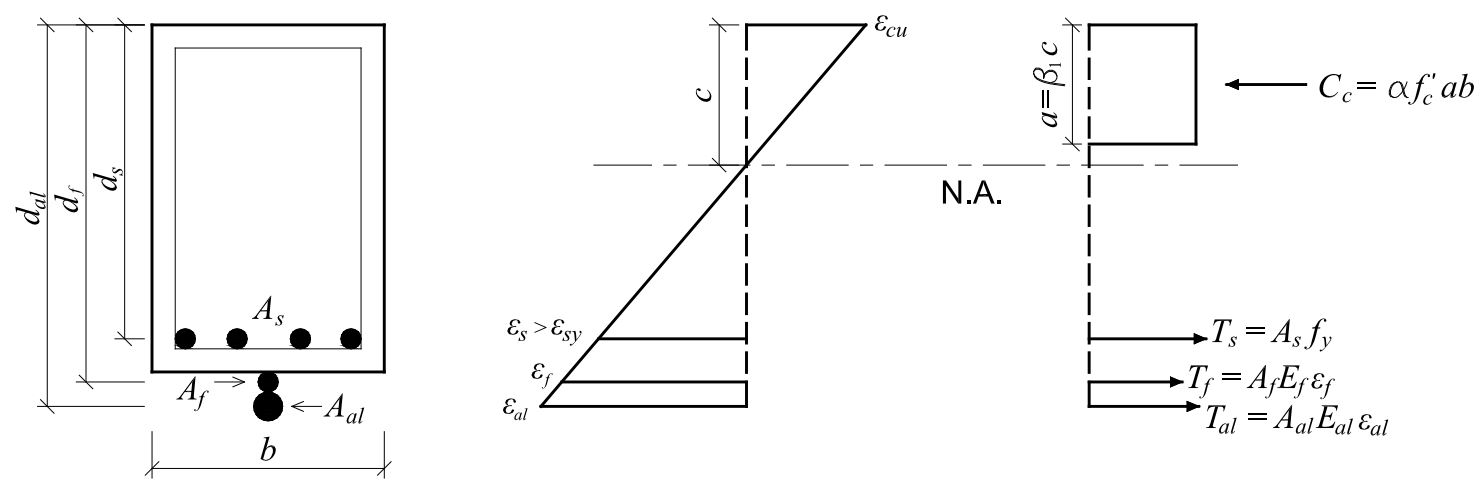

The internal force equilibrium at critical section can be calculated by Equation (1), using strain compatibility from Figure 11.

$$
\alpha f_{\mathrm{c}}^{\prime} a b=A_{\mathrm{s}} f_{\mathrm{sy}}+A_{\mathrm{f}} E_{\mathrm{f}} \varepsilon_{\mathrm{f}}+A_{\mathrm{al}} E_{\mathrm{al}} \varepsilon_{\mathrm{al}}
$$

in which

$$
\begin{gathered}
\varepsilon_{\mathrm{f}}=\varepsilon_{\mathrm{cu}}\left(d_{\mathrm{f}}-c\right) / c \\
\varepsilon_{\mathrm{al}}=\varepsilon_{\mathrm{cu}}\left(d_{\mathrm{al}}-c\right) / c
\end{gathered}
$$

where $\alpha$ is the ratio of equivalent concrete compressive stress under flexure to concrete strength (note that it is typically taken as 0.85 in ACI 318 [30]); $f_{c}^{\prime}$ is the specified compressive strength of concrete; $a$ is the equivalent depth of the rectangular stress block; $b$ is the beam width; $A_{\mathrm{s}}$ and $f_{\text {sy }}$ are the cross-sectional area and the yield strength of tension steel; $A_{\mathrm{f}}$ and $A_{\mathrm{al}}$ are the cross-sectional areas of 
glass-fiber and aluminum; $E_{\mathrm{f}}$ and $E_{\mathrm{al}}$ are the modulus of elasticity of glass-fiber and aluminum; $\varepsilon_{\mathrm{f}}$ and $\varepsilon_{\mathrm{al}}$ are the strain of glass-fiber and aluminum at ultimate, respectively; $\varepsilon_{\mathrm{cu}}$ is the compressive strain at extreme concrete fiber ( $\varepsilon_{\mathrm{cu}}$ was assumed equal to 0.003 ); $c$ is the neutral axis depth; $d_{\mathrm{s}}$ is the distance from beam top to centroid of tension steels; $d_{\mathrm{f}}$ and $d_{\mathrm{al}}$ are the effective depths measured from beam top to centroid of the glass-fiber and aluminum material. If the strain in the glass-fiber or aluminum material exceeds ultimate or yield strain, the modulus of elasticity times strain is equal to ultimate or yield strength of each material (that is, $E_{\mathrm{f}} \varepsilon_{\mathrm{f}}=f_{\text {fu }}, E_{\mathrm{al}} \varepsilon_{\mathrm{al}}=f_{\text {aly }}$ ).

The balanced glass-fiber reinforced ratio $\left(\rho_{\mathrm{fb}}\right)$ can be expressed by Equation (2) when glass-fiber reaches the strain corresponding to $f_{\text {fu, }}$, just as the concrete in compression reaches its assumed ultimate strain of 0.003 . The failure mode of the strengthened beam can be predicted by comparing the balanced $\left(\rho_{\mathrm{fb}}\right)$ and strengthened $\left(\rho_{\mathrm{f}}=A_{\mathrm{f}} / b d_{\mathrm{f}}\right)$ ratios for glass-fiber.

$$
\rho_{\mathrm{fb}}=0.85 \beta_{1} \frac{f_{\mathrm{c}}^{\prime}}{f_{\mathrm{fu}}} \frac{\varepsilon_{\mathrm{cu}}}{\varepsilon_{\mathrm{cu}}+\varepsilon_{\mathrm{fu}}}-\rho_{\mathrm{s}} \frac{d_{\mathrm{s}}}{d_{\mathrm{f}}} \frac{f_{\mathrm{sy}}}{f_{\mathrm{fu}}}-\rho_{\mathrm{al}} \frac{d_{\mathrm{al}}}{d_{\mathrm{f}}} \frac{f_{\text {aly }}}{f_{\mathrm{fu}}}
$$

where $\beta_{1}$ is the factor relating the depth of the equivalent rectangular compressive stress block to the neutral axis depth (note that it is taken as 0.85 for $f_{\mathrm{c}}^{\prime}$ between 17 and $28 \mathrm{MPa}$ in ACI 318 [30]); $f_{\text {fu }}$ and $\varepsilon_{\mathrm{fu}}$ are the ultimate strength and strain of glass-fiber; and $f_{\text {aly }}$ is the yield strength of aluminum.

If $\rho_{\mathrm{f}}$ does not exceed $\rho_{\mathrm{fb}}$, the strain of glass-fiber reaches the ultimate strain prior to the compressive strain of concrete reaching 0.003 . At this time, the nominal ultimate strength $\left(M_{\mathrm{n}}\right)$ of the strengthened beam can be calculated by Equation (3).

$$
M_{\mathrm{n}}=A_{\mathrm{s}} f_{\mathrm{sy}}\left(d_{\mathrm{s}}-\frac{\beta_{1} c}{2}\right)+A_{\mathrm{f}} f_{\mathrm{fu}}\left(d_{\mathrm{f}}-\frac{\beta_{1} c}{2}\right)+A_{\mathrm{al}} f_{\mathrm{aly}}\left(d_{\mathrm{al}}-\frac{\beta_{1} c}{2}\right)
$$

in which

$$
c=\frac{A_{\mathrm{s}} f_{\mathrm{sy}}+A_{\mathrm{f}} f_{\mathrm{fu}}+A_{\mathrm{al}} f_{\text {aly }}}{0.85 f_{\mathrm{c}}^{\prime} \beta_{\mathrm{l}} b}
$$

On the contrary, if $\rho_{\mathrm{f}}$ exceeds $\rho_{\mathrm{fb}}$, then the strain in the concrete reaches 0.003 prior to the glass-fiber reaching its ultimate strain. Since concrete members are designed according to the specification that they not exceed $75 \%$ of the maximum reinforcement ratio $\left(\rho_{\mathrm{sb}}\right)$, the tension steel and aluminum can generally yield. Based on these assumptions, the neutral axis depth (c) of Equation (4) and nominal ultimate strength $\left(M_{\mathrm{n}}\right)$ of Equation (5) can be expressed as follows.

$$
c=\frac{-B+\sqrt{B^{2}-4 A C}}{2 A}
$$

in which

$$
\begin{gathered}
A=0.85 \beta_{1} f_{\mathrm{c}}^{\prime} b \\
B=-A_{\mathrm{s}} f_{\mathrm{sy}}-A_{\mathrm{al}} f_{\mathrm{aly}}+E_{\mathrm{f}} A_{\mathrm{f}} \varepsilon_{\mathrm{cu}} \\
C=-E_{\mathrm{f}} A_{\mathrm{f}} \varepsilon_{\mathrm{cu}} d_{\mathrm{f}} \\
M_{\mathrm{n}}=A_{\mathrm{s}} f_{\mathrm{sy}}\left(d_{\mathrm{s}}-\frac{\beta_{1} c}{2}\right)+A_{\mathrm{f}} f_{\mathrm{f}}\left(d_{\mathrm{f}}-\frac{\beta_{1} c}{2}\right)+A_{\mathrm{al}} f_{\mathrm{aly}}\left(d_{\mathrm{al}}-\frac{\beta_{1} c}{2}\right)
\end{gathered}
$$


in which

$$
f_{\mathrm{f}}=E_{\mathrm{f}} \varepsilon_{\mathrm{cu}}\left(d_{\mathrm{f}}-c\right) / c
$$

Figure 12 illustrates the measured and predicted moment capacity of the tested flexural specimens. It is clear from Figure 12 that a good correlation between the measured and predicted moment-capacity exists. The average and standard deviation between predicted and measured values $\left(=M_{\text {Ana. }} / M_{\text {Exp. }}\right)$ are 1.00 and 0.08 for slab specimens and 1.07 and 0.15 for beam specimens, respectively. The error ranges of $M_{\text {Ana. }} / M_{\text {Exp. }}$ are within $13 \%$ in slab specimens, and the predictions for slab specimens tended to match better than the ones for beam specimens. The prediction for some beam specimens overestimated their strength because the debonding of the AGC beam occurred prior to its yielding during the flexural testing. Although several assumptions for predicting the moment capacity were made in the equation, and premature failure in specimens occurred in some tests, this analysis method provided a good estimation for the moment capacity and can be used for design. However, it should be noted that the debonding of the AGC beam due to lower bonding strength of the epoxy should be considered in further work.

Figure 12. Comparison with measured and predicted ultimate moment capacity.

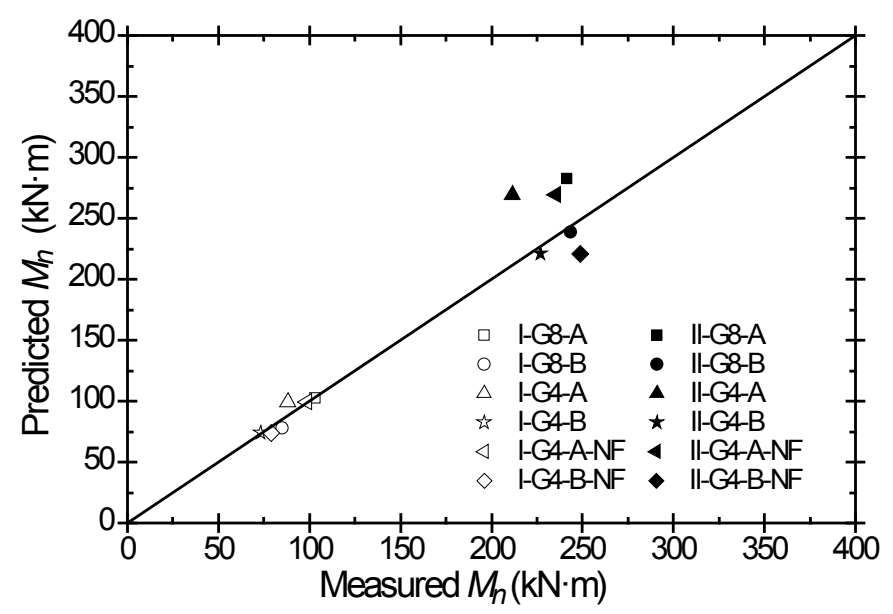

\section{Conclusions}

This study focused on experimental and analytical investigation of the improvement of the flexural performance of concrete members strengthened with an aluminum-glass fiber composite (AGC) beams, which consisted of hollow aluminum and laminated glass-fiber layers. From the flexural test under four-point bending, for specimens strengthened with the externally bonded AGC beam, the following conclusions are drawn:

1. The AGC beam increased the load carrying capacities of initial crack load, yield load, and peak load. However, the failures for the tested specimens showed different local and global failure modes, including the fracture of the AGC beam and debonding from the RC member prior to the ultimate load. In particular, the debonding failure of the AGC beam occurred in most beam specimens of Group II. The enhancement of epoxy bonding strength is needed to prevent premature failure such as debonding. 
2. The AGC beam of the A-type enhanced the flexural stiffness (or strength) more efficiently in slab specimens than in beam specimens. On the other hand, the AGC beam of B-type was better suited for beam specimens than for slab specimens. However, more consideration for ductility in both of A-type and B-type is required for further work.

3. Comparing AGC beams of W80-F20 with W40-F60, the former worked for flexural stiffness or strength more effectively than the latter, but the difference was not significant.

4. The use of fasteners should be considered carefully since fastener installation could lead to fracture of the AGC beam due to stress concentration.

5. The proposed analysis method provided excellent agreement between the experimental and analytical load-carrying capacities of the specimens, even though certain assumptions had to be made for predicting moment capacity.

6. The fasteners used in the form of nails do not seem to be ideal or practical. A better solution would be the use of a U-anchorage so that the inclined shear cracking would not precipitate the debonding of the AGC beam.

\section{Acknowledgments}

The study has been supported by Basic Science Research Program through the National Research Foundation of Korea (NRF) and was funded by the Ministry of Education, Science and Technology (Nos. 20120008837, 2012005170).

\section{Conflicts of Interest}

The authors declare no conflict of interest.

\section{References}

1. Su, R.K.L.; Zhu, Y. Experimental and numerical studies of external steel plates strengthened reinforced concrete coupling beams. Eng. Struct. 2005, 27, 1537-1550.

2. Arslan, G.; Sevuk, F.; Ekiz, I. Steel plate contribution to load-carrying capacity of retrofitted RC beams. Constr. Build. Mater. 2008, 22, 143-153.

3. Barnes, R.A.; Baglin, P.S.; Mays, G.C.; Subedi, N.K. External steel plate systems for the shear strengthening of reinforced concrete beams. Eng. Struct. 2001, 23, 1162-1176.

4. Sudedi, N.K.; Baglin, P.S. External plate reinforcement for concrete beams. J. Struct. Eng. 1998, 124, 1490-1495.

5. Ahmed, M.; Oehlers, D.J.; Bradford, M.A. Retrofitting reinforced concrete beams by bolting steel plates to their sides. Part 1: Behavior and experiments. Struct. Eng. Mech. 2000, 10, 211-226.

6. Smith, S.T.; Bradford, M.A.; Oehlers, D.J. Local buckling of side plated reinforced concrete beams. II: Experimental study. J. Struct. Eng. 1999, 125, 635-643.

7. Su, R.K.L.; Siu, W.H.; Smith, W.T. Effects of bolt-plate arrangements on steel plate strengthened reinforced concrete beams. Eng. Struct. 2010, 32, 1769-1778.

8. Toutanji, H.; Deng, Y. Comparison between organic and inorganic matrices for RC beams strengthened with carbon fiber sheets. J. Compos. Constr. 2007, 11, 507-513. 
9. Toutanji, H.; Zhao, L.; Zhang, Y. Flexural behavior of reinforced concrete beams externally strengthened with CFRP sheets bonded with an inorganic matrix. Eng. Struct. 2006, 28, 557-566.

10. Triantafillou, T.C.; Plevris, N. Strengthening of RC beams with epoxy bonded fiber composite materials. Mater. Struct. 1992, 25, 201-211.

11. Attari, N.; Amziane, S.; Chemrouk, M. Flexural strengthening of concrete beams using CFRP, GFRP and hybrid FRP sheets. Constr. Build. Mater. 2012, 37, 746-757.

12. Balsamo, A.; Nardone, F.; Iovinella, I.; Ceroni, F.; Pecce, M. Flexural strengthening of concrete beams with EB-FRP, SRP and SRCM: Experimental investigation. Compos. B 2013, 46, 91-101.

13. Etman, E.E.; Beedy, A.W. Experimental programme and analytical study of bond stress distributions on a composite plate bonded to a reinforced concrete beam. Cem. Concr. Compos. 2000, 22, 281-291.

14. Lee, H.K.; Hausmann, L.R. Structural repair and strengthening of damaged RC beams with sprayed FRP. Compos. Struct. 2004, 63, 201-209.

15. Lee, J.M.; Burgoyne, C.J. Experimental study of influence of bond on flexural behavior of concrete beams pretensioned with aramid fiber reinforced plastics. ACI Struct. J. 1999, 96, 377-385.

16. Maaddawy, T.E.; Soudki, K. Strengthening of reinforced concrete slabs with mechanically-anchored unbonded FRP system. Constr. Build. Mater. 2008, 22, 444-455.

17. Bank, L.C. Mechanically-fastened FRP (MF-FRP): A viable alternative for strengthening RC members. In Proceedings of the Second International Conference on FRP Composites in Civil Engineering (CICE 2004), Adelaide, Australia, 8-10 December 2004; pp. 3-15.

18. Woo, S.-K.; Nam, J.-W.; Kim, J.-H.J.; Han, S.-H.; Byun, K.J. Suggestion of flexural capacity evaluation and prediction of prestressed CFRP strengthened design. Eng. Struct. 2008, 30, 3751-3763.

19. Xue, W.; Tan, Y.; Zeng, L. Experimental studies of concrete beams strengthened with prestressed CFRP laminates. PCI J. 2008, 53, 70-85.

20. Xue, W.; Tan, Y.; Zeng, L. Flexural response predictions of reinforced concrete beams strengthened with prestressed CFRP plates. Compos. Struct. 2010, 92, 612-622.

21. Dias, S.J.E.; Barros, J.A.O. Performance of reinforced concrete $\mathrm{T}$ beams strengthened in shear with NSM CFRP laminates. Eng. Struct. 2010, 32, 373-384.

22. Ha, G.-J.; Kim, Y.-Y.; Cho, C.-G. Groove and embedding techniques using CFRP trapezoidal bars for strengthening of concrete structures. Eng. Struct. 2008, 30, 1067-1078.

23. Hassan, T.; Rizkalla, S. Investigation of bond in concrete structures strengthened with near surface mounted carbon fiber reinforced polymer strips. J. Compos. Constr. 2003, 7, 248-257.

24. Choi, Y.; Park, I.H.; Kang, S.G.; Cho, C.G. Strengthening of RC slabs with symmetric openings using GFRP composite beams. Polymers 2013, 5, 1352-1361.

25. Moon, D.Y.; Sim, J.S.; Oh, H.S. Detailing considerations on RC beams strengthened with CFRP bars embedded in mortar overlay. Constr. Build. Mater. 2007, 21, 1636-1646.

26. Ombres, L. Flexural analysis of reinforced concrete beams strengthened with a cement based high strength composite materials. Compos. Struct. 2010, 94, 143-155.

27. Ann, K.Y.; Cho, C.G. Constitutive behavior and finite element analysis of FRP composite and concrete members. Materials 2013, 6, 3978-3988. 
28. Si-Larbi, A.; Agbossou, A.; Ferrier, E.; Michel, L. Strengthening RC beams with composite fiber cement plate reinforced by prestressed FRP rods: Experimental and numerical analysis. Compos. Struct. 2012, 94, 830-838.

29. Khalifa, A.; Alkhrdaji, T.; Nanni, A.; Lansburg, S. Anchorage of surface mounted FRP reinforcement. Concr. Int. Des. Constr. 1999, 21, 49-54.

30. American Concrete Institute (ACI) 318 Committee. Building Code Requirements for Structural Concrete (ACI 318-11) and Commentary (ACI 318R-11); American Concrete Institute (ACI) 318 Committee: Farmington Hills, MI, USA, 2011; Chapter 10, pp. 136-137.

(C) 2014 by the authors; licensee MDPI, Basel, Switzerland. This article is an open access article distributed under the terms and conditions of the Creative Commons Attribution license (http://creativecommons.org/licenses/by/3.0/). 